\title{
Service users and carers as co-educators of social work students
}

\section{Rob Mackay ${ }^{1}$, Margot Fairclough ${ }^{2} \&$ Michael Coull $^{3}$}

Summary: This paper considers issues related to the requirement by the Scottish Social Services Council (SSSC) and the Scottish Government that service users and carers are partners and stakeholders in social work education. This requirement is one of many used by the SSSC in the approval of Scottish universities to deliver social work courses.

This paper explains and reflects on the experiences of including service users and carers as co-educators with the social work courses at the Robert Gordon University (RGU) making particular reference to one module. It examines the issues around the process of their involvement with the education of social work students, and considers student evaluations of this module. Lastly it discusses the broader implications for partnership working in relation to the education and training of students for professional practice. The focus is on the role that service users and carers can play as partners in the classroom through the use of personal narratives. The experience of presenting as a service user or carer is discussed and the contributions highlight how such presentations can heighten student awareness as to the lived experience of a disability or a mental health problem.

Keywords: partnership; empowerment; involvement; co-educator; process; personal narratives

1. Lecturer in Social Work

2. Carer

3. Service User

Address for Correspondence: The Robert Gordon University, School of Applied Social Studies, Garthdee Road, Aberdeen AB10 7QG, Scotland r.mackay@rgu.ac.uk

Acknowledgements: We wish to acknowledge the contributions of service users, carers, students and social work staff for the development of ideas in this paper, whilst at the same time making clear our sole responsibility for its contents.

Date of publication: 30th November 2009

95 J. of Practice Teaching \& Learning 9(1) 2009, pp.95-112. DOI: 10.1921/146066909X481484. @ wEbb 


\section{Introduction}

This paper is written by a carer (MF), a service user (MC) and a lecturer in social work (RM). Mostly in this article the collective 'we' is used to indicate a shared view, but from time to time a particular perspective is emphasised, indicated by the use of our initials.

It has been pointed out that adoption of terms such as 'service user' and 'carer' may be problematic due to its contested nature (Warren 2007). We accept that the dichotomy between formal and informal roles does not reflect day to day to reality, whilst at the same time are using 'service user' and 'carer' as these are familiar terms and have meaning for each of us.

\section{Background information}

The Framework for Social Work Education (Scottish Executive 2003) was introduced to modernise social work education and is framed around partnership working in which service users and carers are identified as stakeholders. The Scottish Social Service Council - the regulatory body - applies the Framework as criteria in the approval of social work courses in Scotland. The introduction of the Framework instigated a process of change and development within the School of Applied Social Studies, RGU. This led to the establishment of a Service Users Panel, a Carers Involvement Network and a Young Person's Group. These groups are made up of representatives of service user and carer groups across the North-East of Scotland. These are advisory groups with a remit to consider all aspects of social work courses within the School of Applied Social Studies, RGU. These significant developments have seen a number of innovations including a set of Principles (RGU Service User Panel 2005) to underpin involvement. The Core Principles are:

- No tokenism

- Fair funding

- 'Bottom up' Networks

- All service users and carers have a voice

- See change from consultation

- Respect for privacy and confidentiality

96 J. of Practice Teaching \& Learning 9(1) 2009, pp.95-112. DOI: 10.1921/146066909X481484. @ w\&b 
These developments were assisted by financial resources and administrative procedures that has made it possible for travel expenses to be reimbursed with cash on the day and people also have the choice of claiming a gift voucher.

A further influential report, Changing Lives, was published in 2006 by the 21st Century Social Work Review group chaired by William Rae. The Scottish Executive had commissioned this review. Changing Lives made many wide ranging recommendations as to the possible role of Social Work in the 21st Century. A central recommendation was about the need to 'build capacity to deliver personalised services' (21st Century Review Group, 2006, p.2). This is best explained by the Users and Carers Panel that contributed to the final report:

Services should meet the needs of people. People shouldn't have to fit services. Social workers should be allowed time to get to know their clients really well, so that they really understand the different needs of each individual. (21st Century Review, 2006, p.1)

These external policy drivers emphasised the need that social workers are required in the 21st Century to have skills, knowledge and values that equip them to work in partnership with service users and carers in a way that meets the diverse needs of individuals. It was clear to the social work staff team at RGU, that the political drive to modernise social work services was not simply the preserve of our colleagues in the 'field' but also at University level.

Therefore there was an opportunity, with the introduction of the 'new' social work degree in 2004, to redesign our courses.

It is within this policy context of change and modernisation that the Disability and_Mental Health module was reviewed. The aim of the re-design was to ensure that student social workers would be well equipped to meet the challenges of responding effectively to the very individual needs of people with mental health problems, people with learning disabilities, people with physical disabilities, people with sensory impairments and their families.

The re-designed module was run with seventy BA Degree social work students from January to April 2005 (and then run again in subsequent years.). For the purposes of this paper I will focus specifically on the experience of the 2005 student cohort and will draw upon evaluation evidence provided by these students on completion of the module.

97 J. of Practice Teaching \& Learning 9(1) 2009, pp.95-112. DOI: 10.1921/146066909X481484. @ wEbb 


\section{Background literature}

The use of personal narratives by people with lived experience was seen by the teaching team as a vital ingredient in creating an authentic learning experience. Other names for personal narratives are autobiographies, life stories, and recovery stories, which can be either narrated in oral or written form. Stories are a very direct medium for not only sharing experiences but also as a way of getting a message across.

Human beings are storytellers by nature. In many guises, as folktale, legend, myth, epic, motion picture and television program, the story appears in every known human culture. The story is a natural package for organising many different kinds of information. Storytelling appears to be a fundamental way of expressing ourselves and our world to others.

(McAdams, 1993, p.27)

Prior to 2004, the teaching team had involved service users in the classroom on an ad hoc basis and had witnessed the telling of personal stories about difficult issues in living and the experience of using public services. Our impression was that these stories were able to emotionally move a group of students and enable them to develop other perspectives about groups in society. People with lived experience in mental health and disability were increasingly motivated to use their voice to influence the political agenda and to promote positive change in public services. The reforms in social work education referred to earlier in this paper created openings for a more systematic approach to involving service users and carers in direct teaching with social work students. The argument has been made that social work students need to have involvement with service users and carers, not only on professional placements, but also in the classroom to ensure that the students gain knowledge and understanding not only from theories and research, but also through personal stories that engage students in the experienced reality of people's lives (Advocacy in Action, (2007)

Partnership is a slippery concept, which has an inter-relationship with 'collaboration', 'inclusion', 'involvement', 'participation', and 'empowerment'. There probably is no agreed definition of partnership (Carr, 2004; Warren,2007). However, attention is drawn by a number of writers (Carr, 2004; Beresford \& Trevillion, 1995) as to two different

98 J. of Practice Teaching \& Learning 9(1) 2009, pp.95-112. DOI: 10.1921/146066909X481484. @ wEb 
'models'; one is described as 'consumerist' and the other as 'democratic'. The consumerist model has provided impetus for service providing organisations to seek the views and opinions of those who use services, whilst retaining the control of decisions about policy and resources. Typical techniques used include satisfaction surveys and consultation days. On the other hand, the primary concern with the democratic model is that of empowerment (Mackay, 2007). This is concerned with people having more say and fundamentally for people to be treated with respect. Carr, (2004, p.18) in her analysis of research evidence states:

embedded continuous but varied participation approaches that engage service users in decision making have most potential for active change. The majority of service users wish to represent themselves directly, collectively or through a peer advocate in decision making forums.

The School staff adopted the 'democratic' approach in reaching out to service users and carers and over a period of five years have embedded processes, which will become apparent over the course of this article. Beresford and Trevillion (1995), through an action research project, found that democratic approaches are based around a set of assumptions:

- Communication involves spending time with each other as partners and requires time and commitment to this process.

- This is relational based work in which space and time has to be created to allow productive relationships based on mutual trust and respect

- Awareness as to the power dynamics and a commitment made to the sharing of power

- Open and flexible processes in relation to assessments and decision making

- Producing shared objectives and working towards these.

- Ways of working and the outcomes are constantly under review and open to discussion.

Carr (2004) indicated that not only time is required but also resources to support service user and carer involvement and participation in non-tokenistic ways. She also highlighted that service users and carers need feedback on their participation.

99 J. of Practice Teaching \& Learning 9(1) 2009, pp.95-112. DOI: 10.1921/146066909X481484. @ wEbb 
The democratic approach to partnership working requires not only the incorporation of value based assumptions but also a set of skills to make this happen and inject some vitality into this work. Thompson (2002), in the context of working with families suggests the following as partnership skills:

- Establishing shared goals and plans of actions

- Recognising and building on strengths

- Self awareness

- Mediation skills

- Addressing the emotional dimension

- Recognising and dealing with obstacles in promoting change

This paper will reflect later on how the processes used within the module was underpinned by some of the above ideas.

\section{Delivering the module}

Delivering the module was very much an experience in partnership and networking as it involved quite a number of people, both internal and external to RGU. These included the two receptionists to our building, an administrative officer from the School who ensured service users and carers received their travelling expenses and gift vouchers on the day, seven service users, one carer, four social workers, two voluntary sector workers, one community psychiatric nurse and one consultant psychiatrist.

Service users and carers were involved in person with presenting in Lecture sessions and in a series of Workshops. In addition, the teaching team developed scenarios based around three 'virtual people' (Angela, James, Billy) which included information about each of these 'people' at four different points in their lives. These were used to promote skills development by students in small groups and to consider life cycle perspectives.

100 J. of Practice Teaching \& Learning 9(1) 2009, pp.95-112. DOI: 10.1921/146066909X481484. @ wEb 


\section{Process issues regarding the involvement of service users and carers}

The implementation of an effective approach to involving service users and carers is a long-term process that requires analysis of barriers and then measures put in place that work at two levels:

- to develop support mechanisms at a school and institutional level

- to ensure that on the day of an 'event' that effective processes are in place that supports the individual service user or carer

This recognition of barriers in social work education was evidenced in a paper by Branfield (2007). This paper was the culmination in a piece of action research undertaken by Shaping Our Lives - the national service user network. The barriers to involvement in social work education, it is suggested, include the following:

- Academics do not attach high enough value to service users' knowledge

- The culture in universities needs to change

- Access requirements are not fully met

- Service user organisations lack capacity and infrastructure

- Training for service users and their organisations is lacking

- Payment policies and practices need improving

- The benefits system discourages involvement'

(Branfield, 2007, p.10)

At a School level since 2004 there has been a commitment of staff and financial resources on an ongoing basis, which has been a tangible expression by academic staff that service users and carers do have knowledge forged through personal experience that does contribute to the education of social work students.

What follows is MF's recollection of being involved in a classroom situation for the first time:

The tutor met us at Reception on the day and we relaxed with sandwiches in the staff area, while she discussed what would happen, and where we would fit into the session. In the classroom she reinforced staff expectations of students' behaviour through attentive listening, good body language, appropriate questioning and, vitally, confidentiality. I felt safe. As I listened to the background lecture on the

101 J. of Practice Teaching \& Learning 9(1) 2009, pp.95-112. DOI: 10.1921/146066909X481484. @ wEbb 
supporting legislation, I realised how far RGU tutors were practising exactly what they preached in the way we were being included, respected and supported to grow into an equal and professional role. When I discovered that I easily understood the teaching points (a huge fear) I felt almost unstoppable.

I feel that I am in a human relationship with all the tutors, with trust on both sides. This is why it is not a tokenistic exercise. I could not do something so personal under any other circumstances, and the more I learn of the tutors, the more I feel able to give. I also feel that the students gain something inexpressibly valuable for their future practise by witnessing this process.

Such shared experiences, that has enabled social work lecturers, service users and carers to develop mutual understanding and respect. We contend that therefore the central core is relational based work, which is consistent with the published literature (Beresford \& Trevillion 1995, Thompson 2002).

We referred earlier to the development of a system of payments for service users and carers. To achieve this not only did the Head of School agree to an allocation of funds but an administrative procedure had to be agreed within the University at both the central and the school levels. In our view, the fact that the procedure works smoothly is an achievement. The payment of expenses in cash on the day of the event is a crucial process issue; if this was not in place then the reality is for some service users they could not afford to come to the University. The feedback from service users and carers is they value these gift vouchers because as well as the material value they also have the symbolic value of recognition.

The issue of training is recognised as an important aspect of involving service users and carers. Up until 2009, our practice has operated at an individual level between the class lecturer and the service user and/or carer, in terms of orientation for a particular session. However, earlier this year 'training' in a group took place, which consisted of service users and carers reflecting on personal narratives and how these might be used in a classroom situation that aids the students' learning and at the same time ensures the control of these personal experiences is firmly in the hands of the service users and carers.

$\mathrm{MC}$ recalls this experience:

Having undergone training to look at the presentation of sharing one's life story, which included at the end of the training a condensed presentation with the fellow

102 J. of Practice Teaching \& Learning 9(1) 2009, pp.95-112. DOI: 10.1921/146066909X481484. @ wEb 
group members was at first a daunting prospect. In some ways sharing of my story with a group of students was less threatening than with a group of people I knew! In reality, it was very constructive; it gave me the focus to look at how I might give students some insight into my life, the impact on mental ill health for me as a person and talking about my own personal journey. What was an unexpected and added bonus about doing this was the group bonded/gelled in a way that was very supportive, caring and brought us closer together.

\section{MF recalls her experience of these training sessions:}

I have gained greatly during 2009 from being offered several workshops to focus our thoughts and the material we present to students. I was very wary of being subtly influenced into some sort of political correctness, or being morphed into too professional a style of presentation, which I could not manage comfortably. I did not know the tutor very well at the start, which affected my confidence too. I was probably stroppy and certainly challenging, all of which was comfortably accepted, and gave me space to really think about how much I choose to reveal about my family, how that will affect us both in future, and why I am subjecting myself to this. I would not have thought so deeply at home on my own. We also discussed and practised presentation styles, how to structure our messages more clearly, and the key points we wanted the students to take away. We all bonded supportively. The workshops left me better prepared earlier this month to talk to students on the Disability and Mental Health Module. My co-presenter was a service user who had also participated in the same workshops; as a result we gained strength and focus from each other, and, I think, presented a very cohesive message. I found that I could discuss more openly how my son's condition had affected both of our lives, because I had been given space in these workshops to think deeply about what felt safe for me to reveal.

These comments provide positive encouragement that this process, which could be called capacity building, has much to offer in terms of a real engagement with the challenging process of educating students in which there is a recognition that a classroom situation is not the place for catharsis. The personal experiences that are shared must have an educational purpose and rationale closely allied to the objectives of a particular class and indeed the whole module.

At the same time, there is a constant need for the lecturers to remember that the stories that service users and carers bring into the classroom are no fabricated case studies but emerge out of real human

103 J. of Practice Teaching \& Learning 9(1) 2009, pp.95-112. DOI: 10.1921/146066909X481484. @ wEbb 
situations in which there is always an emotional component however many times the person has told the same story.

MF recalls becoming quite tearful at one point:

The tutor and I had discussed this possibility earlier, and she had the confidence to allow me to continue. I feel strongly that it is good for the students to witness the depth of emotion that lies behind our experiences, and to learn (in a safe environment for them) how to sit with high emotion. The tutor, I and the students all seemed to cope well. Afterwards we had plenty of time to wind down and reflect on our experience with the tutor before leaving. I valued this because I needed to hear that I had 'got it right' for the students. I felt that real support would be there for us if anything difficult emerged from what we had done. It was really lovely to receive a note of appreciation afterwards, which added to the sense of contribution and value.

MC adds his perspective:

In terms of the personal issues that presenting my story to students it was important for me to be mindful that I was sharing my story and by doing so it could be emotive for me. However - and to balance that - it was beneficial in the sense that I can also put my story into perspective for the students and, more importantly for me. One of the good things I found about sharing story is that when I'm presenting it that I'm one step removed in some ways because although I'm talking about my own experiences, when I'm doing its with hindsight and any of the 'baggage' I had at the time long since gone it is factual and in perspective.

These comments from MF and MC underscore the need for lecturing staff to have good levels of awareness as to how a particular class might well generate emotions not only for the presenters but also for the study body. It seems to us this statement has major implications for the process as to how a class session may be run and the potential learning that may be generated. The following comments are based on an assumption that a member of lecturing staff will be present in the classroom with students, service user and carer.

\section{Prior to the class taking part}

The lecturer needs to ensure that the presentation by the service user/

104 J. of Practice Teaching \& Learning 9(1) 2009, pp.95-112. DOI: 10.1921/146066909X481484. @ w\&b 
carer is embedded into a well-planned series of classes. He or she will meet beforehand with the service user/carer to share information about the module, what has gone beforehand and then to negotiate in an open and flexible way as to the purpose of the forthcoming session. This requires negotiation, a willingness to share power (Beresford $\&$ Trevillion 1995) and a recognition that the service user/carer has strengths and finding the best way (Warren 2007; Branfield 2007) for this person to get their point across. For some people they may prefer to make a presentation, whilst for others it may be that they find the interview method most appropriate. An explicit and very clear agreement needs to be made at this point (Beresford $\&$ Trevillion, 1995; Thompson, 2002).

The lecturer needs to provide the students with prior information about this session and to remind them as to their professional responsibilities. We have developed a written protocol which is issued to students to reinforce these expectations.

\section{The class itself}

There are process issues about ensuring the service user/carer is welcomed upon entering the building (a well-informed receptionist is worth her weight in gold) and is guided to the right room at the right time! Doing the class together is a visible demonstration of sharing power and often proceeds in flexible and open ways. This might include, as the carer has stated above, an open expression of emotion, which in our experience is usually congruent with the situation been described and for the students offers a complimentary diet to that of conceptual based knowledge. It does require the lecturer to be comfortable with expressed emotions and to have the skills to facilitate the session effectively (Thompson 2002).

\section{Post-class reflections}

There is always an immediate post-class reflections together along the lines indicated in the comments by the carer stated above, often over a cup of coffee.

Lecturing staff will seek feedback from the student group and indeed

105 J. of Practice Teaching \& Learning 9(1) 2009, pp.95-112. DOI: 10.1921/146066909X481484. (c) wEbb 
there can be a follow-on activity based on the presentation by the service user/carer. The lecturer will then share the feedback with the service user/carer either in a face to face to meeting or by a card or a letter or by e-mail.

\section{Student Evaluation}

A questionnaire was developed that was framed around the module objectives and asked students to complete this at the end of the module. $86 \%$ of students considered that the staff team had been extremely successful or very successful in ensuring that the module is populated with the lived experiences of service users and carers.

$82 \%$ of students rated the module overall as either excellent or very good relevant.

The device of the 'Virtual Persons' (Angela, James and Billy) proved to be effective for ongoing learning and debate within the seminar groups. $78 \%$ of students considered their use to be either Very Good or Excellent.

The students were generous with their written comments about the impact of listening to service users and carers. These comments were subjected to a thematic analysis and the following themes were identified:

- Impact of real life stories

- Dispelling myths and stereotypes

- Develop Insights

- Theory \& Practice

- Alerted them to an another area of practice,

Very commonly, the students described the Impact of real life stories; that these personal accounts highlighted the area under discussion in class as relating to the reality of peoples' lives and that they might well encounter as social workers. The following comment by a student is representative of this perspective

It is the service users and carers input that make it real

This module raises major issues to do with stigma, discrimination

106 J. of Practice Teaching \& Learning 9(1) 2009, pp.95-112. DOI: 10.1921/146066909X481484. @ wE-b 
and exclusion and this can prove to be an awakening experience for some students. Many of the students in their comments spoke about how listening to service users and carers helped to Dispel their own myths $\&$ stereotypes. The following comment was made about one session in which a person who hears voices shared some of this experience and also made a number of powerful points about good social work practice.

It had an impact on myself and my colleagues; any stigma that might have been attached was gone and my perceptions changed while my understanding grew.

Some indicated that listening to these personal stories helped them to Develop insights into the human side of living with a long-term disability or illness. This alluded to understanding more about the emotional dimension as is represented in this student comment:

The man who was carer for his wife gave a very honest view of both their feelings.

And most encouragingly from a teaching perspective some students made the link between these personal narratives and the teaching content of the module. In other words they made the connection between theory and practice.

It made theories fit into place and made the whole area more real

These personal accounts Alerted some students to a valuable area of practice by making them aware as to the issues and what was required to work in this area. This contributed to students forming a more favourable view of work in a particular area:

I thought what he (service user) had to say made me more interested in working with mental health as it has not interested me before.

\section{Discussion}

Partnership and social inclusion are current social policies in all aspects of public services. The question arises as to whether service users and carers are partners. If the answer is yes, then are they to be regarded as

107 J. of Practice Teaching \& Learning 9(1) 2009, pp.95-112. DOI: 10.1921/146066909X481484. (c) wEbb 
partners in the same light. If so, what conditions and processes need to be in place that create the opportunity for service users and carers to participate with partnership endeavours in non-tokenistic ways?

At the very heart of this discussion is the understanding of 'partnership' because as has been pointed out (Beresford \& Trevillion, 1995; Turner \& Balloch, 2001), this term has been so widely used, in different contexts and sometimes tokenistically, that its currency may have been devalued. We are articulating a shared view of a model of partnership working that is based on principles of empowerment (Mackay 2007), that strives to be power sharing, non-tokenistic and inclusive of service users, carers and social work lecturers. 'Co-educators' was included in the title for this article to communicate that the education and training of people to be professional social workers for the challenges of the 21st Century is a shared and joint one. The views of Advocacy in Action resonate with our own experiences:

Partnership won't happen overnight. We all have to work at it. To the query 'Is it honestly worth the effort?' we would wholeheartedly reply 'Immeasurably so. (Advocacy in Action, 2007, p.62)

A sensitive application of partnership principles has been the basis for the work that has been undertaken within the School of Applied Social Studies. This involves many aspects of which practical and financial supports are important but the very core has been the building of trusting relationships between the service users/carers and members of the module team. The building of trust and mutual respect opens the door for all sorts of possible co-operations. This mirrors the experience of the Shaping Our Lives project (Branfield et al., 2006) which found that one of the advantages of an ongoing project is that the various stakeholders have the opportunity to:

- get to know one another as individuals

- gain more understanding as to the other's perspectives

- create a space that promotes mutual trust and confidence

There may be a criticism of this approach that it is too individualised, too emotional and insufficiently evidence-based. Service users and carers are invited to come and speak about their experiences to groups of students - these can be emotionally powerful experiences. Can one

108 J. of Practice Teaching \& Learning 9(1) 2009, pp.95-112. DOI: 10.1921/146066909X481484. @ w\&b 
person's story about a disability truly inform students about a particular disability in an evidenced manner? What is the purpose of such an exercise when professional lecturers are hard pressed to deliver evidence based theoretical material in relatively brief timescales?

A key point that is made to the students on this module is that every person has their own individual journey through disability or a mental health problem and so it is stressed that the speaker is sharing her own experience. For example, the person who speaks about hearing voices shares her experience of this but also makes it clear that other people have different experiences of hearing voices. What sort of knowledge might be generated by such presentations?

MC states:

I see the purpose of it as both a teaching and learning tool. For the lecturers it is a means of illustrating/humanising the theory and in a way that compliments/reinforces it. I think the impact that my story has on students does help with their learning and, for want of a better term, might help the 'penny drop' in terms of them giving them a personal insight that will take with them into their practice placements and ultimately impact on their practice as social workers. More importantly, it also illustrates to students that the people they may work with come from all walks of lives - there are times in our lives when we need help, support and guidance and that services users and carers can be just as 'learned' as them and it is only through circumstances that we become a service user or carer. Taking part in the whole teaching session from beginning to end has been most valuable to me - having just undertaken three teaching sessions it was heartening to see how the lecture and the carer and my own contribution completed the circle with regard to the workshop and helped it become more cohesive and hopefully - and I'm unsure if this is the right word - 'enjoyable' for the students.

This learning process we suggest is enhanced through the use of personal narratives. Personal testimony is able to connect people and convey complex issues through the medium of stories. It has been suggested by Walnum (2007) that service users and carers bring to the classroom 'experience knowledge' (Walnum, 2007, p.9) and indeed from personal knowledge some mental health service users refer to themselves as experts by experience.

Walnum (2007) is not excluding the value of professional knowledge but does suggest that the combination of both makes for something exciting: 
In fact, when 'professional knowledge' and 'experience knowledge' are mixed, it's dynamite! (Walnum, 2007, p.9)

An example of this is the joint session RM shares with a service user about hearing voices. RM in reflecting about his presentations over the years on the same subject matter with no service user contribution, considered these lacking in connections with real situations. Similarly, it is unlikely that the service user on her own would evoke similar student feedback. However when she and RM work in partnership, then the students are asked to engage with both 'experience knowledge' and 'professional knowledge'. It is then that synergistic process is created in the classroom in which the possibility for authentic learning to take place has been created. Our experience in having service users and carers as partners in the classroom has been a consistently positive experience. As much student feedback has indicated they very much value the opportunity to hear from a 'real' person (as distinct from a lecturer!). We suggest that these sessions 'open doors' for students and enable them to reflect on their own pre-conceived stereotypes and begin the process of opening up and contextualising the meaning of 'schizophrenia', 'deafness', and 'autism'.

In pedagogic terms, it can be observed that the presentation from a service user or carer often can have an initial emotional impact as it is a real event. The module team uses a variety of strategies to re-enforce the learning throughout the remainder of the module. A visual image of a swimming pool comes to mind; the initial 'splash' is created by the presenter and then the ripple effect is maintained through the use of workshops and the seminar groups over the duration of the module.

This short paper suggests there are benefits for student learning if we invite service users and carers to become partners in the teaching/ learning process.

There are also benefits for teaching staff and indeed for the University itself as a public institution on the basis that an ongoing relationship allows for good partnership working. This enables the University and its staff to be viewed positively and from that vantage point further developments are more likely. At the same time this paper has discussed the need to avoid tokenistic moves through ensuring a sound organisational commitment is made and putting in place enabling structures and processes.

110 J. of Practice Teaching \& Learning 9(1) 2009, pp.95-112. DOI: 10.1921/146066909X481484. @ wEb 


\section{Conclusion}

MC concludes that the experience of presenting:

my personal story for me is very positive in a number of ways that I will elaborate on. As someone who has experienced mental ill health and inevitably the stigma and labelling that accompanies it, it's important for me to give students some insight and understanding of these issues in a way that will compliment their learning in a way that is both constructive and also an awareness of the challenges that people living with mental ill health have to face.

This paper suggests attention to the process of involving service users and carers is fundamental to ensuring there is a positive learning experience for students, service users and carers.

The impact on student learning is in line with policy and practice and is very much in step with the Changing Lives Report (Scottish Executive 2006). It is about developing the capacity of the social services workforce to work in a way that recognises and embraces the aspirations and resources of service users and carers. This includes recognising the strengths of service users and carers and using supports to find the best ways by which they can share this 'experience knowledge' (Walnum, 2007, p.9) with student social workers.

Developing knowledge, skills and values for practice from a blend of lived experience and professional evidence is a challenging and exciting journey. It demands good partnership working skills and above all an attitude shift to recognise the expertise of people who use services and their contribution as co-educators. The key question is - are you ready for this challenge?

\section{References}

Advocacy in Action (2007) Why bother? The truth about service user involvement. in L. Lymbery and K. Postle (Eds.) Social Work: A companion to learning. London : Sage

Beresford, P. and Trevillion, S. (1995) Developing Skills For Community Care. Aldershot : Arena

Branfield, F., Beresford, P., and Levin, E. (2006) Common Aims: Strategies to

111 J. of Practice Teaching \& Learning 9(1) 2009, pp.95-112. DOI: 10.1921/146066909X481484. @ wËb 
support service user and carer involvement in social work education.London: Shaping Our Lives/SC

Branfield, F (2007) Shaping Our Lives. Www.shapingourlives.org.uk/ documents/SUL_report_V5.pdf [ccessed 10.08.09]

Carr, S. 2004 Has Service User Participation Made a Difference to Social Care Services? Position Paper No. 3 London: Social Care Institute for Excellence (available online at www.scie.org.uk/publications/positionpapers/pp03summary.pdf [accessed 23/09/07]

Mackay, R. 2007 (2007) Empowerment and aAdvocacy. in J. Lishman (Ed.) Handbook of Theory for Practice Learning in Social Work. London: Jessica Kingsley

McAdam, D.P. (1993 The Stories We Live By. New York: Guilford

RGU Service User Panel Leaflet (2005) (available online at http://www.rgu. ac.uk/files/Service\%20User\%20leaflet.doc)

Scottish Executive (2003 Framework for Social Work Education in Scotland. Edinburgh: Scottish Executive

Scottish Executive (2006) Changing Lives: Report of the 21st Century Social Work Review. Edinburgh: Scottish Executive

Thompson, N. (2002) 'Building the Future. Lyme Regis: Russell Hous

Turner, M. and Balloch, S. (2001) Partnership between service users and statutory social services. in S. Balloch and M. Taylor (Eds.) Partnership Working. Bristol: Policy Press

Walnum, E. (2007) Sharing stories:the work of an experience consultant. International Journal of Narrative Therapy and Community Work, 2, 3-9

Warren, J. (2007) Service User and Carer Participation in Social Work. Exeter : Learning Matters

21st Century Social Work Review Group (2006) Changing Lives. (Executive Summary available online at http:www.scotland.gov.uk/ Publications/2006/02/02094408/4) [accessed 22/09/07]

112 J. of Practice Teaching \& Learning 9(1) 2009, pp.95-112. DOI: 10.1921/146066909X481484. @ wEb 